\title{
DisimilaCión COMO DESHISTORIZACIÓN en el pensamiento de Franz Rosenzweig
}

\author{
Roberto Navarrete Alonso \\ The Franz Rosenzweig Minerva Research Center \\ The Hebrew University of Jerusalem, Israel \\ roberto.navarrete.alonso@gmail.com
}

Resumen

Este artículo propone una interpretación del Centro Libre de Estudios Judíos de Fráncfort fundado por Franz Rosenzweig en 1920 y su correspondiente programa educativo como aplicaciones prácticas del antihistoricismo de Rosenzweig, entendido éste como fundamento último de su disimilacionismo, es decir, de sus críticas tanto al asimilacionismo como al sionismo de su tiempo. Dicha interpretación se basa en una lectura del proyecto educativo rosenzweiguiano, Ya es hora, en conexión con el tercer libro de La Estrella de la Redención y, en particular, con la concepción metapolítica y metahistórica del judaísmo que cabe encontrar en él.

Palabras clave: deshistorización, disimilación, formación judía, Franz Rosenzweig, historicismo. 


\section{Dissimilation as Dehistorization in \\ Franz RosenzWeig's Thought}

Abstract

This papers deals with an interpretation of the Freies Jüdisches Lehrhaus founded by Franz Rosenzweig in 1920 and his educational program as practical applications of the Rosenzweigian anti-historicism, which will be here understood as dissimilation, that means, as a critique against assimilationism and zionism contemporaries to Rosenzweig. This interpretation will be based on a reading of the Rosenzweigian educational project, Zeit ist's, in relation to the metapolitical and metahistorical conception of Judaism which can be found in the third book of The Star of Redemption.

Keywords: Dehistorization, Dissimilation, Franz Rosenzweig, Historicism, Jewish education. 
El propósito del presente artículo es presentar el programa educativo para el judaísmo alemán de Franz Rosenzweig, esbozado en Ya es hora (1917) e implementado por su autor en el Centro Libre de Estudios Judíos (Freies Jüdisches Lehrhaus) por él fundado en Fráncfort del Meno (1920), como aplicación práctica del antihistoricismo que impregna La Estrella de la Redención (1921). De este modo, la Lehrhaus de Rosenzweig es concebida en este trabajo como puesta en acto de la actitud de resistencia, entendida ésta como ser-en-elmundo-y-sin-embargo-contra-el-mundo, que se sigue de una concepción mesiánica del tiempo histórico como la que determina el modo en que Rosenzweig entiende lo real, esto es, la relación entre Dios, hombre y mundo. ${ }^{1}$ Se propone aquí, en definitiva, leer el proyecto de renovación de la formación judía en conexión con la tercera parte de La Estrella, así como con la crítica formulada por Rosenzweig contra las tendencias asimilacionista y sionista propias del judaísmo de su época. Para ello se procederá del siguiente modo: en primer lugar, se expondrá una historia sumaria $-\mathrm{y}$, por tanto, no exhaustiva- de la secularización o historización del judaísmo europeo en relación a su emancipación, es decir, desde la Edad Media hasta el siglo XIX y, por tanto, el surgimiento, en Alemania, de las Ciencias del Judaísmo (Wissenschaft des Judentums) ${ }^{2}$ en segundo lugar, se situará a Rosenzweig en la corriente historicista alemana representada por su primer maestro, Friedrich Meinecke, y se ubicarán las raíces del antihistoricismo rosenzweiguiano en la concepción del judaísmo

1 La expresión "ser-en-el-mundo" no debe entenderse aquí en sentido específicamente heideggeriano, aun no siendo pocas las afinidades entre las respectivas propuestas filosóficas de Heidegger y Rosenzweig. Sobre este parentesco, pero también sobre las diferencias existentes entre estos dos enormes pensadores, pueden consultarse, junto al clásico de Karl Löwith (2006), el trabajo de Peter E. Gordon (2003) y, en especial, las valiosísimas aportaciones de Bernhard Casper al respecto (1985, 1996 y 2005).

2 No se pretende aquí, en ningún caso, hacer una revisión de la historiografía judía del Medioevo al siglo XIX, lo cual efectivamente resultaria desproporcionado y, por lo demás, materialmente inviable en un trabajo como el presente. De lo que se trata es, en cambio, de contextualizar, siquiera mínimamente, la reacción antihistoricista de Rosenzweig contra las Ciencias del Judaísmo de su época. A tal fin, se seguirá aquí la monografía de David N. Myers (2003), discípulo de Yosef Hayim Yerushalmi, sobre el descontento de algunos prominentes judíos alemanes de principios del siglo XX respecto del historicismo. 
formada por Rosenzweig a partir de sus contactos tanto con Eugen Rosenstock como con, fundamentalmente, el segundo de sus maestros: Hermann Cohen. En tercer lugar, se presentarán las líneas fundamentales del proyecto rosenzweiguiano de renovación de la formación judía en la Alemania de entreguerras y, por último, se establecerá un nexo entre el trasfondo antihistoricista de este programa educativo y el significado teológico-político del tercer libro de La Estrella de la Redención.

Secularización e historización del judaísmo europeo

Si la historiografía moderna, en tanto que civil y, por lo tanto al servicio del soberano, surgió como consecuencia del conflicto entre lo sagrado y lo profano, es decir, del proceso de secularización de las instituciones públicas, el judaísmo constituyó, al menos hasta su emancipación definitiva como resultado del triunfo de la Revolución Francesa, una auténtica anomalía (Myers, 2003: pp. 14ss.). A la excepcionalidad política del pueblo hebreo que significó su pervivencia al margen de un Estado soberano propio y en el interior de múltiples Estados en los que los judíos no eran siquiera reconocidos como ciudadanos, le correspondería una excepcionalidad histórica de acuerdo con la cual el pueblo hebreo carecería de todo carácter histórico en sentido moderno, es decir, permanecería al margen de la secularización y continuaría habitando aquel tiempo sagrado que, en su calidad de ciudadanos del Estado, no sería ya el propio de los gentiles (cristianizados), protagonistas de la historia profana. A diferencia de los pueblos del mundo, por lo tanto, los judíos no habrían sido capaces de -ni acaso habrían necesitado- liberar su propia historia de la mano de Dios ni, por consiguiente, de valorar los acontecimientos históricos al margen de toda teología, o sea, desde un punto de vista secular.

La atención de los judíos a la historia profana debió coincidir, por lo tanto, con su interés en la participación de los asuntos públicos en igualdad de condiciones, esto es, con su deseo de emancipación, que en este sentido es idéntico al deseo de negar su propio carácter 
excepcional y, por consiguiente, al deseo de asimilación, en el sentido de normalización. La aparición de una historiografía judía se sitúa, así, en el origen del proceso de secularización que habría llevado a los miembros del pueblo judío a alcanzar la categoría de ciudadanos en aquellos Estados en cuyo interior habitaban. Significa, por lo tanto, una radical puesta en cuestión del excepcionalismo histórico del judaísmo cuyos orígenes remotos deben datarse en el siglo XVI. Aunque quepa referirse a una historiografía judía medieval, la apreciación de la historia en sus propios términos por parte del judaísmo surge a lo largo del siglo XVI a través de figuras como A. de Rossi (c. 1513-1578), E. Capsali (c. 1483-1555) y D. Gans (1541-1613). Este último pone en relación la historia profana o gentil y la historia sagrada de su propio pueblo, inaugurando el tránsito hacia un nuevo modo de pensar la historia por parte del judaísmo. Aunque en su obra Tsemah David (1592) lo profano y lo sagrado son claramente separados, el mero hecho de reconocer el valor de ambas esferas supone ya una novedad en relación a las crónicas judías medievales. Sin pasar a ser un pueblo más entre las naciones del mundo, los descendientes de Abraham y de Sara dejan de ignorar la historia de los gentiles y, lo que es si cabe más importante, se refieren a una parte de la historia humana, la de los goyim, sin necesidad de recurrir a intervención divina alguna. La yuxtaposición de una historia judía o sagrada, por un lado, y una historia gentil o profana, por otro, confiere a la obra de Gans el sentido histórico que, como conditio sine qua non suya, estaría a la base del historicismo judío característico de la primera generación de intelectuales que, ya en el siglo XIX, se dedicaron en Alemania al cultivo de las Ciencias del Judaísmo. Entre la corriente historiográfica judía del siglo XVI y el historicismo judío decimonónico no hay, en cualquier caso, vacío alguno, sino una paulatina historización de la conciencia que el judaísmo europeo y, particularmente, la judería alemana, tenía de sí misma. Los nombres de Baruc Spinoza (1632-1677) y Moses Mendelssohn (1729-1786) dan cuenta de este proceso.

En el caso de quien, con el permiso de Thomas Hobbes (15881679), puede ser considerado el fundador del estudio crítico de la Biblia, puede hablarse de una radicalización de la postura de Gans. 
Si éste admitía ya la importancia de la historia profana, pero la distinguía aún de una historia sagrada reservada al Pueblo Elegido, en su Tratado teológico-político (1770) Spinoza pondrá en cuestión el valor eterno de la Revelación del Sinaí e incluso la autoría misma del Pentateuco, que la tradición judía atribuía a Moisés en calidad de intermediario entre Dios y su pueblo (Spinoza, 1976: pp. 48-102). La crítica histórico-filológica de las Sagradas Escrituras llevada a cabo por Spinoza significaba, de este modo, la negación del carácter sacro de la narrativa bíblica y su transformación en mera historia profana. Menos de un siglo después de que los primeros historiadores judíos admitieran la posibilidad y el valor, al menos en el caso del paganismo, de una historia exenta de toda intervención divina, otro judío, no sin razón expulsado de la sinagoga de Amsterdam, negaba todo carácter sagrado a la historia de su propio pueblo.

La radicalidad de la crítica bíblica llevada a cabo por Spinoza se verá atenuada por las consideraciones de Mendelssohn a propósito de la revelación. A diferencia de aquel, el primer representante del judaísmo alemán, como buen hijo de la Ilustración, sentía una mayor inclinación hacia la elaboración de un sistema holístico de pensamiento que hacia la contextualización de acontecimientos históricos concretos. Para Mendelssohn, como para Kant, la historia debía estar subordinada a las ambiciones sistemáticas del pensamiento filosófico. Sin embargo, aparece en el filósofo judío como una categoría ontológica relevante, una fuente de autoridad capaz de confirmar acontecimientos religiosos de tanta importancia como el de la propia Revelación del Sinaí. La posición de Mendelssohn con respecto a la historia fue, por lo tanto, ambivalente, hasta el punto de que cabría situar en él el origen del debate entre judaísmo e historicismo. Si bien no cabe afirmar que el historicismo judío alcanzó su madurez, ni en la práctica ni en la teoría, con Mendelssohn, la conciencia histórica del judaísmo inaugurada por la historiografía judía del siglo XVI y radicalizada por Spinoza en el XVII encontró en el programa de reforma educativa diseñado y puesto en práctica por sus discípulos, los maskilim o judíos de la haskalah o "Ilustración judía”, el camino hacia la historización de la cultura judía europea y, 
concretamente, alemana, característica del siglo XIX y comienzos del siglo XX (Myers, 2003: pp. 20-30). También, de acuerdo con lo señalado más arriba, hacia la emancipación y, en último término, la asimilación de la judería a la cultura europea.

Rosenzweig y el historicismo alemán: la influencia de Friedrich Meinecke

Al contrario de lo que cabría pensar, no fue el historicismo judío aquel con el que, en un primer momento, hubo de habérselas Rosenzweig. Sólo una vez que el filósofo de Kassel comprendió e hizo la experiencia de las consecuencias relativistas a las que conducía el método historicista, decidiéndose entonces por la permanencia en la fe judía, su mirada pudo dirigirse hacia la academia secular del judaísmo. Mientras tanto, el joven Rosenzweig, incapaz de encontrar lugar alguno al judaísmo en un mundo, aunque secularizado, absolutamente cristianizado, vivió más bien bajo el influjo del historicismo de Friedrich Meinecke, esto es, del historicismo alemán: la fe en el individuo histórico proclamada por vez primera por quien en algún momento fue, a pesar de la subordinación de la historia al sistema que como se ha indicado caracterizó el pensamiento del filósofo de Köninsberg, discípulo de Kant: Johann Gottfried Herder (1744-1803). ${ }^{3}$ A él remitirá Meinecke cuando, ante la crisis del historicismo anunciada por Ernst Troeltsch (1865-1923), rearticule en su libro sobre El historicismo y su génesis (1936) las premisas de lo que el maestro de Rosenzweig consideró no sólo una nueva concepción de la historia, sino toda una revolución en el pensamiento occidental. Se trataba, en general, de una liberación de la historia con respecto a las leyes de naturaleza basada en el siguiente supuesto fundamental: a diferencia de los estáticos e inmutables principios de la ley natural, el individuo histórico evoluciona y se desarrolla

3 Para un estudio más detallado de la relación entre Rosenzweig y Meinecke, es decir, entre Rosenzweig y el historicismo alemán de su tiempo, así como de su relación con Hegel, cuyo desarrollo en el presente trabajo resulta inviable, véase mi artículo“Franz Rosenzweig y la crisis del historicismo alemán" (2015), también el estudio conclusivo de los Escritos sobre la guerra de Franz Rosenzweig (2015), escrito junto con Patxi Lanceros. Por supuesto, la referencia en esta materia sigue siendo Stephane Mosès (1987, 1988 y 2003). 
de manera ininterrumpida, de tal manera que la tarea del historiador, del hombre dedicado al cultivo de la ciencia histórica, debía consistir en proporcionar una densa descripción contextual de dicha evolución. Este modo de concebir la ciencia histórica está dotado de un alcance metodológico e ideológico: por un lado, exige del historiador que su estudio de una persona, evento, nación o era trate su objeto como una individualidad que se desarrolla durante un periodo de tiempo a través de sus propias posibilidades internas; por otro, descansa en una cosmovisión que otorga un gran valor al pasado, concebido éste como un conjunto de organismos históricos individuales conectados entre sí.

Ambos aspectos están presentes tanto en los estudios de Meinecke sobre la relación entre cosmopolitismo y nacionalismo y sobre la idea de razón de Estado en la Edad Moderna, como en el estudio rosenzweiguiano sobre el origen y el devenir de la idea hegeliana de Estado: Hegel und der Staat (1920). De una parte, maestro y discípulo compartieron un tratamiento de las ideas como inseparables de las vidas en las que se formaron y las instituciones a las que afectaron y a través de las cuales se realizaron, como individualidades históricas susceptibles de ser estudiadas a partir de una interpretación historicista de la historia de las ideas (Ideengeschichte) como la introducida por Meinecke en su obra Weltbürgertum und Nationalstaat (1908). De otra, esta aproximación metodológica a la historia de las ideas y de la política debía servir, al menos en principio, para fortalecer el denominado historicismo ético: la visión de la historia política de acuerdo con la cual ésta consiste en la evolución de la relación entre kratos - poder-y ethos - eticidad-. Ambos, según Meinecke, habrían coincidido por primera vez, en el plano de las ideas, a través de Hegel, y, en la realidad política, a través del Imperio bismarckiano (1983: pp. 364-379). La crítica de Rosenzweig a la idea hegeliana de Estado, así como al realismo político de Otto von Bismarck, constituyen por ello el punto de partida de la reacción anti-historicista de Rosenzweig, consumada a partir de 1917 como consecuencia del fracaso alemán en la Gran Guerra. ${ }^{4}$ Éste es, en definitiva, el causante

4 Sobre esta cuestión debe tenerse en cuenta, naturalmente, el Hegel de Rosenzweig, en especial su Prólogo y su Conclusión, añadidos ambos en 1920, pero también los escritos políticos de juventud del autor de La Estrella, recogidos en los Gesammelte 
del rechazo, por parte de Rosenzweig, tanto de la conexión hegeliana entre ideas e historia como del historicismo de Meinecke. La re-evaluación de la historia llevada a cabo por Rosenzweig a partir de 1917 es efecto de su desengaño político. La afirmación de un judaísmo metahistórico y metapolítico representa en este sentido su inconformista modo de resistir, en el más alto grado posible, frente a los horrores del matadero de la historia (Avineri, 1988).

La convicción de que una gran oportunidad para la historia universal se había perdido, en la medida en que el realismo político de cuño bismarckiano se había mostrado incapaz de responder a la vocación histórico-universal de Alemania que la guerra había puesto de manifiesto - la creación de un gran Estado supranacional centroeuropeo-, afectó, por lo tanto, a la visión rosenzweiguiana de la historia. Su rechazo de la historia universal se revela en la glorificación de la separación del pueblo hebreo con respecto a los peligros de la política y la historia que se encuentra en La Estrella, pero también en el hecho de que, al término de la guerra y de la redacción de su opus magnum, Rosenzweig profundizó en su relación con la sinagoga, como estudioso de sus textos sagrados, como hombre de oración y como maestro de sus correligionarios (Mendes-Flôhr, 1988: p. 157).

\section{Las fuentes del antihistoricismo rosenzweiguiano: Eugen Rosenstock y} Hermann Cohen

Fiel a la certeza por él adquirida en 1917, Rosenzweig mantuvo una actitud coherente con su desengaño histórico-político al rechazar la prestigiosa posición en la universidad que Meinecke había conseguido para él (GSI, 2: p. 679). ${ }^{5}$ El historiador perfectamente "habilita-

Schriften (GSIII: pp. 241-368), de los que ha aparecido recientemente una traducción al castellano como Escritos sobre la guerra (2015), al cuidado de quien escribe.

5 Véase también, sobre la relación de Rosenzweig con la posibilidad de habilitarse y, en general, con la universidad, su carta a Martin Buber del 12 de enero de 1923 (GSI, 2: pp. 878-879). El escepticismo de Rosenzweig con respecto al valor real de una carrera académica viene expresado ya, no obstante, muy pronto, en una entrada de su diario fechada el 20 de noviembre de 1906 (GSI, 1: p. 65). 
ble" (habilitierbar) que había concluido en 1914 un riguroso estudio sobre la génesis y el desarrollo del concepto hegeliano de Estado no podía ya, al término de la guerra, suspender el juicio con respecto a lo sucedido en ella, mostrarse indiferente ante los acontecimientos históricos de su tiempo y continuar cultivando una disciplina, la de la ciencia histórica, cuyo método y cuya ideología de fondo habían sido radicalmente puestos en cuestión por el propio acontecer histórico. No se trataba, por lo tanto, de un rechazo de la historia per se cuanto de la ciencia histórica tal y como ésta había venido cultivándose en Alemania desde el siglo XVIII. El propósito era más bien el de salvar a la historia de los peligros del historicismo, en la línea de la revolución anti-historicista que, desde la teología y la filosofía, llevó a cabo una parte importante de la intelectualidad alemana -Karl Barth, Rudolf Bultmann, Friedrich Gogarten, los hermanos Ehrenberg, Eugen Rosenstock y, por supuesto, Martin Heidegger- durante la tercera década del siglo pasado, inmediatamente después del final de la guerra (Myers, 2003: pp. 69-70 y 95-100).

No cabe la menor duda de que la Primera Guerra Mundial, la crisis y la tragedia del pueblo alemán, disiparon la pasión de Rosenzweig por la historia, alimentada fundamentalmente por el historicismo de Meinecke. No obstante, las raíces del anti-historicismo teológico de Rosenzweig pueden y deben ser rastreadas, no sólo en su desengaño político, sino también en la crisis de identidad y de fe que sufrió a mediados de 1913, tras la conversación con Rosenstock que se sitúa en el origen de su progresiva disimilación o judaización, así como, por consiguiente, en su contacto con la religión, anunciado ya a Hans Ehrenberg, a propósito de la divinización hegeliana de la historia, en carta fechada el 23 de septiembre de 1910:

Dios debe redimir al hombre, no a través de la historia sino, en realidad - no hay otra alternativa-, como "Dios de la religión" [...] La lucha contra la historia en el sentido del siglo XIX es para nosotros, por ello, al mismo tiempo, lucha por la religión en el sentido del siglo XX (GSI, 1: pp. 112-113). 


\section{a. La conversación nocturna de Leipzig}

Esta referencia a la religión como un ámbito de experiencia distinto y en realidad superior a la historia, constituiría un tópico clave en las conversaciones de Rosenzweig con algunos de los participantes en una convención de jóvenes historiadores y filósofos celebrada en Baden-Baden en 1910, que más tarde formarían, junto con el joven discípulo de Meinecke, el Círculo de Patmos (Patmos-Kreis), en alusión al autor del Apocalipsis: los hermanos Ehrenberg y el propio Rosenstock. Fue éste quien movió a Rosenzweig desde el historicismo hacia un punto de vista basado en la idea de revelación, así como al abandono de la filosofía hegeliana de la historia a la que Rosenzweig se había aferrado aún en Baden-Baden y, más tarde, de la historia de las ideas de Meinecke, en aras de un filosofar que sólo considera a la historia como "Reino intermedio" (Zwischenreich) y pone el énfasis en el aspecto escatológico, el final y la meta de la historia: la redención.

Rosenstock acusó a Rosenzweig, no sin razón, de mantener una posición historicista y, por consiguiente, en la línea de la crítica de Heinrich Rickert (1863-1936) - cuyos seminarios, como los de Meinecke, frecuentaba Rosenzweig en la época de Friburgo- al mentor académico del autor de La Estrella, relativista y nihilista. Tuvo cierto éxito, como el propio Rosenzweig reconoció, a la hora de desplazarle de dicha posición, no sólo a través de la correspondencia mantenida por ambos a partir de 1916, sino desde la misma conversación nocturna de Leipzig, origen de la crisis de identidad y de fe del joven historiador judeo-alemán (GSI, 1: p. 133). ${ }^{6}$ Rosenstock fue capaz de sosegar en su interlocutor la hybris de la disciplina historicista, que desatendía a la verdadera naturaleza de la experiencia religiosa. Así ocurría, por ejemplo, en el caso del neoprotestantismo alemán del siglo XIX, que tendía a equiparar la esencia de la fe cristiana con la

6 Junto a la experiencia de la guerra, se trata del acontecimiento de mayor trascendencia en la corta vida de Rosenzweig. La interpretación canónica -y hagiográfica- de este episodio, a cargo de Nahum N. Glatzer (1961), ha sido recientemente puesta en cuestión, de modo exhaustivo y riguroso, por Benjamin Pollock (2014). 
personalidad histórica y la enseñanza en vida de Jesús. ${ }^{7}$ Era también el tono fundamental adquirido en Alemania por las Ciencias del Judaísmo, no en vano profundamente influenciadas por el protestantismo cultural alemán.

A través de su conversación con Rosenstock, Rosenzweig fue capaz de reconocer por primera vez el carácter artificioso de todo ordenamiento del mundo en términos históricos, si bien hasta 1917 se mantuvo en una posición profundamente ambivalente a este respecto, ya que un ordenamiento tal seguía siendo, a sus ojos, epistémicamente inevitable. ${ }^{8}$ La influencia de Rosenstock, no obstante, tuvo más que ver con tres elementos fundamentales de la obra capital de Rosenzweig: el concepto decididamente anti-marcionita de revelación, la relación entre cristianismo y judaísmo y la idea de un filosofar en la forma de calendario. Las condiciones previas del rechazo rosenzweiguiano del historicismo, radicalizado posteriormente a consecuencia del desengaño político del todavía historiador, deben, sin embargo, encontrarse más bien en la perspectiva ganada por Rosenzweig a través de las lecciones y el trabajo sobre la religión de la razón de Hermann Cohen. Será a través de la influencia de su maestro en las fuentes del judaísmo que Rosenzweig, como muestra su "Teología atea" (Rosenzweig, 2014: pp. 323-337), conecte el antihistoricismo teológico con la oposición al sionismo político, es decir, los caracteres metahistórico y metapolítico que definirán en su opus magnum el modo de ser judío. Por lo demás, debe recordarse asimismo que Rosenzweig proyectó junto con Cohen una reforma de las Ciencias del Judaísmo en abierta oposición al historicismo que, heredado de la ciencia protestante de la religión, había encontrado arraigo en buena parte de la intelectualidad judía. El proyecto no fue

7 Ejemplo por antonomasia de ello es Das Leben Jesu, kritisch bearbeitet (1835-1836), obra de David Friedrich Strauss (1808-1874). En ella, el teólogo alemán retrataba al Jesús histórico, llegando a negar su naturaleza divina. Tal y como se desarrollará más abajo, Rosenzweig dedicó a este estudio unas páginas críticas en el temprano ensayo antihistoricista y de contenido teológico titulado "Teología atea" (Rosenzweig, 2014: pp. 323-337).

8 Incluso después de 1917, en la propia Estrella, seguirá valiendo, al menos, en el caso del cristianismo. 
llevado a cabo de manera conjunta como consecuencia de la muerte de Cohen en 1918. La Academia para las Ciencias del Judaísmo (Akademie für dieWissenschaft des Judentums) fue creada en 1919, si bien estuvo determinada desde sus orígenes mismos, bajo la dirección de Eugen Täubler (1879-1953), por una marcada impronta historicista, al contrario de lo deseado por Cohen y Rosenzweig. El proyecto de ambos, sin embargo, fue inspirador del ulterior Centro Libre de Estudios Judíos.

\section{b. Filosofía, judaísmo y antihistoricismo: Hermann Cohen}

Sin ser quizá consciente él mismo de ello, debe contarse a Cohen entre aquellos que inauguraron un discurso crítico contra el historicismo - en su caso, fundamentalmente judío- que emergió en el interior de la academia secular. En un primer momento, como representante de la escuela neokantiana de Marburgo, frente a la escuela de Baden encabezada por Wilhelm Windelband (1848-1915) y el ya mentado Rickert, centró su atención en cuestiones epistemológicas, entendiendo la identificación de los a priori lógicos de la conciencia humana como la tarea propia y autónoma de la filosofía. En lugar de cerrar filas en torno a la causa de la historia, a la manera de Wilhelm Dilthey (1833-1911) en su Introducción a las ciencias del espíritu de 1813, o incluso del propio Windelband, su respuesta ante el apogeo de la historia y la pérdida de credibilidad del sistema especulativo de Hegel, es decir, ante la crisis de la filosofía, consistió así en reservarle al pensamiento filosófico una esfera propia aunque, en comparación con el hegelianismo, muy modesta.

Sumido en el protestantismo cultural alemán, a pesar de su judeidad y del antisemitismo reinante en la moderna burguesía alemana de la época, su ruptura con la historia no fue, a pesar de todo, absoluta. ${ }^{9}$ Mantuvo la distinción entre Geschichte -historia como pro-

9 Cohen se sintió cómodo en el mundo cultural del protestantismo, hasta el punto de que sus perspectivas filosófica, política y religiosa adoptaron una cierta orientación protestante. Así, cuando su mentor en Marburgo, F. A. Lange (1828-1875), le preguntó en una ocasión si existía entre ellos una diferencia religiosa profunda, Cohen fue tajante: "No, porque lo que tú llamas cristianismo yo lo llamo judaísmo profético" (citado en 
greso-e Historie - historia como disciplina-y trató de, en cierto sentido à la Nietzsche, salvar alguna utilidad de la historia sin sucumbir al historicismo, es decir, de resolver la tensión entre lo empírico, historisch, y lo a priori, geschichtlich, convirtiendo a la disciplina que tiene a lo primero como su objeto material en una empresa de gran alcance prescriptivo, no meramente descriptivo. No fue ésta, sin embargo, la razón por la que, pocos meses después de la conversación nocturna de Leipzig, Rosenzweig decidió trasladarse durante algún tiempo a Berlín y asistir allí a las lecciones que Cohen venía impartiendo desde 1912 en el seminario rabínico liberal de la ciudad. No era la filosofía coheniana, per se, lo que interesó a Rosenzweig sino, en primer lugar, la defensa pública, llevada a cabo desde la universidad, del judaísmo al que Cohen había retornado en 1880, dos décadas después de abandonar el seminario de teología judía de Breslau, así como las muestras de responsabilidad y de solidaridad para con sus correligionarios judíos en plena oleada de antisemitismo. ${ }^{10}$

Desde entonces y hasta su muerte en 1918, la obra y la vida, tanto pública como privada, del judío representante de la universidad alemana, estuvo determinada por su convicción de que tanto el judaísmo al que había retornado como la filosofía kantiana en que se había formado representaban sistemas racionales orientados a la fundamentación de una ética. Al mismo tiempo, el idealismo kantiano, a través de su filosofía de la historia, y el judaísmo, a través de su tradición profética, coincidirían, según Cohen, en atribuir a esta ética el papel de una eternidad histórica, es decir, de telos de la historia

Myers, 2003: p. 46). Años más tarde, el filósofo de Coswig reformuló esta posición señalando que en referencia al concepto científico de religión se sentía "incapaz de descubrir diferencia alguna entre el monoteísmo judío y el cristianismo protestante" (citado en Myers, 2003: p. 47). En su introducción a los escritos judíos de Cohen, el propio Rosenzweig señaló a este respecto, muy probablemente teniendo a su maestro en mente, que: "Todos los judíos modernos y, sobre todo, los judíos alemanes, son protestantes" (Rosenzweig, 1998: p. 30). Por lo demás, Jacques Derrida fue, si cabe, más explícito al referirse directamente a Cohen como “judeo-protestante” (Derrida, 2004: pp. 39-128).

10 Rosenzweig identifica el retorno de Cohen al judaísmo con la publicación, en 1880, de Ein Bekenntnis in der Judenfrage (Cohen, 1924: pp. 73-94) como respuesta a la crítica que Heinrich von Treitschke había vertido sobre la historia del judaísmo de H. Grätz, antiguo maestro de Cohen (Rosenzweig, 1998: pp. 28ss.). 
-entendida ésta, obviamente, no como Historie sino como Geschichte: aproximación progresiva hacia un futuro ideal-. El reino kantiano de los fines y la redención, la esencia de la religión de la tradición profética hebrea, eran para Cohen una y la misma cosa: la manifestación ética de una razón cuyo contenido sustantivo es inalcanzable para una metodología historicista. Aunque ninguna labor académica pueda proceder sin historia, su metodología resulta insuficiente para llevar a cabo una aproximación sustantiva al judaísmo, es decir, para distinguir en él lo esencial y lo inesencial, precisamente aquello que Cohen pretendía hacer en sus seminarios - y en su obra póstuma, La religión de la razón desde las fuentes del judaísmo- y que despertó el interés de Rosenzweig. Desde entonces, la interpretación que éste hizo del judaísmo al que, como Cohen, había retornado, no sólo se alejó de todo historicismo sino que vio en él un obstáculo, de hecho el más peligroso de su tiempo, para la revitalización de un judaísmo alemán que, a su juicio, agonizaba, estrangulado por el sionismo y la asimilación de la que el primero no dejaba de ser, en opinión de Rosenzweig, sino una variante nacionalista del camino judío hacia el mundo abierto por la emancipación y la consiguiente historización o secularización del pueblo hebreo. Asimilacionismo y sionismo representaron para Rosenzweig variaciones de un mismo proceso de cristianización del judaísmo y, en esa misma medida, de un mismo proceso de normalización, en el sentido de transformación del Pueblo Elegido en un pueblo más entre los pueblos del mundo, o bien de disolución en ellos (GSI, 1: pp. 304ss. y 398ss.; Kohr, 2008: pp. 37ss.). La oposición a la politización del pueblo de Dios pasaba así, de acuerdo con Cohen y con Rosenzweig, por una superación del historicismo en las ciencias del judaísmo. Tal sería, a juicio de ambos, la condición de posibilidad de una existencia judía espiritual y cultural verdaderamente rica, un mundo judío que, en cuanto tal, debía permanecer al margen de la historia de los pueblos del mundo a la que tanto el sionismo como el asimilacionismo trataban de devolverle.

A pesar de la distancia filosófica existente entre ambos -tanto el historicismo como el neokantismo, en cuanto manifestaciones diversas de un mismo academicismo, oscurecían para Rosenzweig 
el camino hacia la vitalidad genuina, impedían el verdadero salto a la existencia-, así como de la diferencia generacional y contextual existente entre maestro y discípulo, éstos mantuvieron desde 1914 y hasta la muerte del primero en 1918 una extraordinaria colaboración en esta dirección. El proyecto de renovación de las ciencias del judaísmo, inspirado en la docencia del propio Cohen en Berlín, fue concebido por Rosenzweig en 1917 bajo el sugerente título, tomado de Salmos 119, 126: Zeit ist's (GSIII: pp. 461-481). ${ }^{11}$ Sin embargo, el primer fruto de la nueva perspectiva anti-historicista adquirida por Rosenzweig, primero a través de la conversación nocturna de Leipzig con Rosenstock y, más tarde, por medio de su contacto con Cohen, poco tuvo que ver con las consideraciones a propósito de la educación a las que se dedicó Rosenzweig a partir de finales de 1916, no sólo en relación al judaísmo alemán, sino también a la población no judía de Alemania. ${ }^{12}$ Se trató más bien de una crítica llevada a cabo desde el punto de vista de la revelación y dirigida contra el historicismo reinante en la ciencia protestante de la religión, en concreto contra Das Leben Jesu de David Friedrich Strauss, así como contra el sionismo que, bajo la idea de una teología del pueblo judío, defendía ya por entonces, Martin Buber. Uno y otro representaron para Rosenzweig dos casos flagrantes de lo que el filósofo de Kassel denominó "Teología atea". ${ }^{13}$

11 Hay traducción al castellano, como "Ya es hora. Ideas sobre el problema de la actual formación judía", en Rosenzweig, 2007: pp. 29-53.

12 En efecto, Ya es hora fue concebido por Rosenzweig como la contrapartida judeoalemana de Volksschule und Reichsschule (GSIII: pp. 371-411), un programa educativo de corte centroeuropeo, acorde a la idea de Centroeuropa en la que Rosenzweig, durante la Primera Guerra Mundial, depositó sus esperanzas en relación al pueblo alemán. Elaborado algunos meses antes -comenzó a escribirlo en otoño de 1916, mientras que Ya es hora data de comienzos del año siguiente-, lo consideró el hermano rubio de su programa educativo para la judería alemana (GSI, 1: 369). El fracaso del sueño centroeuropeísta de Friedrich Naumann y Theodor von Bethmann-Hollweg le arrebató todo su sentido, como el propio Rosenzweig reconoció en carta a su madre, el 13 de octubre de 1918 (GSI, 2: 612). Desde entonces sólo cabía ya, para Rosenzweig, intentar salvar al judaísmo alemán.

13 El escrito fue redactado a comienzos de 1914, como respuesta a la invitación del propio Buber para colaborar en el segundo anuario de Von Judentum, que finalmente nunca llegó a ver la luz. Por lo demás, respecto de las dudas que el sionismo despertaba 
Teología atea

Este escrito anti-historicista de Rosenzweig pone claramente de manifiesto los encuentros de su autor con Rosenstock y con Cohen, concretamente en lo que hace a la creciente agitación que provocó en él el historicismo, tanto como método para las ciencias de la religión como en calidad de forma del incipiente nacionalismo político judío. De una parte, conforme a la distinción de Cohen entre lo esencial y lo inesencial en religión, Rosenzweig pone en cuestión la premisa nuclear del historicismo en el que se enmarca la investigación de Strauss sobre el Jesús histórico: la posibilidad de una coexistencia efectiva de la perspectiva mundana e individualista propia del historicismo con el universalismo característico de toda religión monoteísta. La audacia epistemológica del autor de La vida de Jesús consistiría, según Rosenzweig, en referirse a la esencia de la religión cristiana a través de una investigación historiográfica sobre la vida del individuo "Jesús" sin tener en cuenta su profundo enraizamiento en la experiencia de la revelación, es decir, no contemplando la religión desde el punto de vista de Dios - lo eterno, esencial- sino del hombre -lo contingente, accidental-. Lo divino es así comprendido, en definitiva, como proyección humana, incurriendo de manera flagrante en el antropocentrismo.

en Rosenzweig, merece la pena traer aquí a colación una anécdota, ya de la época de la Lehrhaus, relativa a un jovencísimo Leo Strauss. Éste, en 1929, describía al autor de La Estrella como "el más libre y fuerte de los judíos que escriben en lengua alemana" (Strauss, 2008: p. 447) y, un año más tarde, dedicó una de sus grandes obras, el estudio sobre el Tratado teológico-político de Spinoza, Die Religionskritik Spinozas (1930), "a la memoria de Franz Rosenzweig" (Strauss, 2008: p. 18), cuyo Nuevo Pensamiento, según confesión a Gershom Scholem en 1935, había suscitado en él un interés inmediato (Strauss, 2008b: p. 715), hasta el punto de situarle (quizá al lado de Carl Schmitt) en el origen de su interés por el problema teológico-político (Strauss, 2008b: pp. 8-9). Rosenzweig, sin embargo, no parecía tener una impresión demasiado buena del joven sionista que fue Strauss. El 6 de diciembre de 1924 se refería así a una de sus colaboraciones en el Centro Libre de Estudios Judíos: "Leo Strauss habla en la Lehrhaus en enero sobre "Teoría del sionismo político". Le dejo hacerlo encantado porque durante mucho tiempo no se ha dado la palabra al estúpido [dumm] sionismo en la Lehrhaus [...] Sin embargo, quiero, en conexión directa, es decir, a primeros de febrero, también en dos o tres horas con discusión posterior, acabar con él dialécticamente ante los mismos oyentes, a saber, con el correspondiente tema contrario" (GSI, 2: p. 1007). 
Lo mismo, si bien en sentido inverso, ocurriría de acuerdo con Rosenzweig en el segundo caso de teología atea por él analizado: si Strauss había humanizado lo divino en la figura de Jesús, la teología buberiana del "judaísmo del pueblo" (Volksjudentum) había incurrido en el acto inverso de deificar lo humano, en este caso bajo la forma de la nación judía. Ésta es considerada por Martin Buber, según quien más tarde fue a pesar de todo estrechísimo colaborador suyo en la "alemanización" (Verdeutschung) de la Biblia hebrea, como una realidad humana propia del positivismo científico que, en esa misma medida, se despide del contenido de la fe (Rosenzweig, 2014: pp. 329-331). Por ello, trataría de fundar en el propio pueblo la fe perdida en la revelación divina, entendiendo nuevamente la divinidad como una proyección humana que tiene su origen en la historia, el pueblo, en lugar de en la eternidad, la elección por medio de la cual Dios se revela a su pueblo. Es esta revelación, y no la historia, la que determina la relación entre Dios y su pueblo, así como la que mantiene la tensión metafísica entre lo esencial -Dios, a quien se subordina la historicidad de la historia por medio de su acción histórica- y lo inesencial -los hombres sometidos al flujo de la historia, situados entre el primer comienzo y el cumplimiento final de la palabra, entre el pueblo del Sinaí y la humanidad mesiánica- (Rosenzweig, 2014: pp. 336-337). Ella permite, por fin, pensar al pueblo judío - en tanto que realidad histórica- como Pueblo Elegido -en tanto que realidad eterna- y, por lo tanto, impidiendo su completa historización, tener acceso a su especificidad constitutiva. ${ }^{14}$

Hasta este punto, la crítica anti-historicista de Rosenzweig, en lo que respecta al judaísmo, centró su atención en la teología del pueblo judío que Buber empleaba para legitimar el sionismo al que hubo de enfrentarse dos años más tarde el propio Cohen. Buber, según

14 En un gesto que sin lugar a dudas anticipa la interpretación del judaísmo que expondrá en La Estrella, Rosenzweig establecerá en 1915 una correspondencia entre esta cuestión, la de la relación de Dios con su pueblo a través de la revelación, con la de su relación con el mundo y, más concretamente, con la tierra. Lo hará en “Deutschtum und Judentum" (GSIII: pp. 169-175), un texto elaborado -y no publicado, por expreso deseo de Rosenzweig, que muy probablemente no quiso ofender públicamente a Cohen- inmediatamente después de la aparición del trabajo homónimo del filósofo de Coswig y como respuesta crítica contra él. 
Rosenzweig, dejaba de lado el contenido sustantivo del judaísmo, su condición de Pueblo Elegido por medio de la revelación divina, y, de acuerdo con la cosmovisión historicista en la que, a su juicio, se sustentaba, elevaba lo relativo a la categoría de esencial. Sin embargo, este modo de proceder no era propio únicamente del sionismo. La otra corriente interna en la que se había dividido el judaísmo desde su emancipación, el asimilacionismo, operaba de manera idéntica: estrangulando, a base de mundaneidad, su condición más propia. En este caso, no haciendo del pueblo de Dios un pueblo más entre las naciones del mundo, sino disolviéndolo como pueblo, desnacionalizándolo si se quiere, dentro de los pueblos en los que habitaba y cuya nacionalidad pasaba a hacer propia.

En lo que respecta a la cuestión del anti-historicismo teológico de Rosenzweig que, esbozado entre mediados de 1913 y principios de 1917, representará un elemento determinante de la relación entre teología y política tal y como ésta será presentada en La Estrella de la Redención, resta dar cuenta aquí del proyecto de reforma educativa para la judería alemana diseñado por el filósofo de Kassel con el apoyo de Cohen (1924b: pp. 210-217). A su vez, no obstante, Ya es hora puede ser considerado como la primera intervención activa de Rosenzweig en la cuestión interna del judaísmo, es decir, en el enfrentamiento entre, precisamente, los líderes del judaísmo liberal, tendente en su mayoría hacia la asimilación, y del sionismo político.

Si las líneas de batalla en el interior del judaísmo alemán habían sido claramente definidas en 1916 a través de la polémica entre el anti-sionista Cohen (2010: pp. 261-279) y el sionista Buber (1916a: pp. 281-289; 1916b: pp. 425-433), Rosenzweig esbozó a través de su escrito sobre la educación judía una tercera vía posible, resistente tanto frente a la completa integración social del judaísmo en Alemania como a la inmigración sionista hacia Palestina. Situado en la disyuntiva de ambas alternativas, Rosenzweig apostó por la creación de un mundo específicamente judío en el seno de un territorio y una cultura extraños mediante el establecimiento de un programa educativo específicamente judío. De un lado, el escrito de Rosenzweig se dirige, de manera implícita y sin tematizar lo ya expuesto en "Teología atea”, contra el sionismo: el mundo judío al que se refiere no 
se asienta en territorio palestino, sino en suelo alemán. Sin embargo, se trata al mismo tiempo, fundamentalmente, de la exigencia de una orientación completamente nueva de la política del judaísmo liberal en Alemania, así como de la exhortación a enfrentarse a los deseos de asimilación del liberalismo alemán no judío, que veía en dicha asimilación la solución definitiva a la cuestión judía. En la línea de su anti-historicismo teológico, del mismo modo que critica la historización sionista del judaísmo, Rosenzweig hace pasar dicha re-orientación por situar en los márgenes de las ciencias del judaísmo el interés por la historia o, en todo caso, por poner el inesencial conocimiento de la historia del pueblo judío al servicio de lo esencial para el judaísmo, aquello que es necesario para su supervivencia de manera independiente o incluso contrapuesta a sus alrededores no judíos. ${ }^{15}$ Estos no poseen al mundo judío en su interior, sino que se sitúan a su lado, como enfrentados a él. El mundo judío, lo esencial del judaísmo, a diferencia del cristianismo, consiste en que no debe ser sentido "como algo preliminar a ese otro mundo [el alemán, en este caso] que lo abarca, o como un mero elemento de éste" (Rosenzweig, 2007: p. 33).

En relación al cristianismo, lo distintivo del judaísmo es más que un poder del pasado, más que una curiosidad en el propio tiempo: se trata de una realidad futura que, en cuanto tal, es un mundo propio, aparte del que le rodea (Rosenzweig, 2007: pp. 33-34). Tal, el mundo de la sinagoga. Recuperar el lazo con ella, perdido por la mayoría de los judíos alemanes en algún momento a partir de la emancipación, esa es la tarea de la instrucción religiosa específicamente judía $-\mathrm{O}$ judeoalemana- esbozada por Rosenzweig en Ya es hora (Rosenzweig, 2007: pp. 31-32). ${ }^{16}$ En ese lazo el judaísmo se juega la conservación

15 Así lo explica Rosenzweig. “No se trata de crear un centro emocional para el ámbito de las cosas mundanas, un ámbito en el que al estudiante ya lo introducen las demás asignaturas, sino de nada menos que introducirlo a una "esfera judía" propia, en esencia independiente del resto del universo educativo" (Rosenzweig, 2007: p. 32).

16 En este sentido: "El aula siempre será apenas la antecámara de donde parte el camino hacia la participación en el culto de la congregación. La comprensión viva y activa del culto divino es el filamento en torno del que puede cristalizarse lo que el judaísmo necesita en todo momento para su continuidad: un mundo judío" (Rosenzweig, 2007: p. 34). 
de su esencia y, en este sentido, su supervivencia en cuanto pueblo dotado de una especificidad propia que le separa del resto de pueblos del mundo: su elección, en definitiva, o el hecho de que mantiene una relación especial con Dios a través de su inmediata revelación - es decir, no mediada por un individuo particular ni, por lo tanto, por la historia-. Rosenzweig se refiere ya aquí al carácter metahistórico y, en consecuencia, metapolítico del judaísmo, salvaguardado por la santidad de su lengua, especialmente cuando ésta se emplea para la oración, y en aquel dominio en el que, según el filósofo de Kassel, mejor se expresa la independencia del mundo judío: el "año sagrado" tal y como lo fija el calendario judío (Rosenzweig, 2007: p. 35; EdR, pp. 355-397). En estos dos elementos, y no en la historia, se cifra, junto con la Torá, la esencia o el mundo del judaísmo: aquello que en el individuo judeo-alemán distingue su judeidad de su germanidad y por cuya conservación, al contrario que las corrientes sionista y asimilacionista, variaciones de un mismo historicisimo, quiere velar el proyecto educativo rosenzweiguiano.

Conclusión:formación y resistencia en el pensamiento de Franz Rosenzweig

Es de sobra conocido que, en La Estrella de la Redención, Rosenzweig caracterizará estos tres elementos - la lengua, el año litúrgico y la ley- como el núcleo mismo de la especificidad judía, esto es, de la vida judía (EdR: pp. 356ss.). Aquello que había de ser enseñado en el Centro Libre de Estudios Judíos, entonces, era exactamente lo expuesto en el tercer libro de La Estrella como característico del auténtico mundo judío. Ya es hora data de 1917, es decir, de la época inmediatamente anterior a la redacción de La Estrella. Existe por tanto una íntima relación, tanto cronológica como temática, entre el programa educativo rosenzweiguiano y la cristalización del Nuevo Pensamiento en la obra capital de Rosenzweig. La cuestión es, en ambos casos, una y la misma, lo cual ejemplifican a la perfección los tres esbozos de lecciones sobre "La ciencia de Dios", "La ciencia del hombre" y "La ciencia del mundo" que cabe encontrar en los Gesammelte Schriften de Rosenzweig y que recientemente han sido traducidos al 
castellano (Rosenzweig, 2014: pp. 104-134, 135-48 y 149-161, respectivamente). El contenido de estos bocetos se corresponde, en lo fundamental, con el de los tres capítulos del primer volumen de $\mathrm{La}$ Estrella, dedicados a los tres elementos del ante-mundo (EdR: pp. 41132). Cabría afirmar que, por medio de estas lecciones, Rosenzweig trató de dar a conocer el contenido de su obra principal, siquiera en una versión simplificada. Esto vale, naturalmente, también, y acaso especialmente, en el caso de la temporalidad aconteciente, mesiánica, que constituye uno de los temas centrales, si no simplemente el centro de gravedad mismo, de la obra mayor de Rosenzweig. ${ }^{17}$ Por supuesto, en tanto que alternativa al historicismo, es la consumación del proceso de deshistorización de su propio judaísmo que cabe encontrar en nuestro autor y al que hemos venido refiriéndonos hasta ahora. Aquello sobre lo que, a modo de conclusión, quisiéramos llamar aquí la atención, es el hecho de que la crítica rosenzweiguiana al historicismo, consumada en la exposición de la concepción del tiempo histórico que cabe encontrar en La Estrella, posee un significado teológico-político fundamental y que, por lo tanto, el Centro Libre de Estudios Judíos debe ser entendido como la aplicación práctica, política, en el mundo efectivo, del antihistoricismo de La Estrella. En la Lehrhaus no se trataba sólo, en definitiva, de explicar el contenido de la obra capital de Rosenzweig, sino de que ésta cobrase vida, de hecho conforme a la estructura misma del libro, cuyas primeras palabras son, en efecto, Vom Tode - es decir, "de la muerte"-y, las últimisimas, Ins Leben - esto es, "hacia la vida”-(Bensussan, 2003: p. 18).

El mundo cuya creación trató Rosenzweig de propiciar por medio de su Lehrhaus no era otro que ese mundo doble del que, a propósito del judaísmo, nos habla en La Estrella: "Todo lo que en él sucede posee dos relaciones: por una parte, se refiere a este mundo, pero también se refiere al mundo por venir” (EdR: p. 366). Precisamente aquí, como ha señalado Bernhard Casper (2006: p. 190), se

17 En efecto, la cuestión aparece recurrentemente, no sólo en las lecciones ya citadas, sino en otras igualmente recogidas en El país de los dos ríos: el "Esbozo del saber judío" o en la "Introducción al pensar judío" (Rosenzweig, 2014: pp. 165-166 y 190-218, respectivamente), así como el escrito, de 1920, "Formación sin final" (Rosenzweig, 2014: pp. 167-182). 
encuentra el aspecto decisivo del pensamiento rosenzweiguiano de la temporalidad desde un punto de vista teológico-político. De un lado, "mundo" debe significar siempre el mundo concreto, pero, de otro, representa siempre, a cada momento, un horizonte profético de esperanza que, por lo demás, no debe ser pensado como una meta (Ziel) a la que se aspira eternamente y respecto de la cual sólo cabe una aproximación asintótica, sino como un final (Ende) que viene desde el comienzo, es decir, que acaece, en el presente, como futuro prolépticamente anticipado. Una concepción tal de la temporalidad nada tiene que ver con el futuro pensado por el historicismo, sino con un futuro mesiánico que en último término presupone la confrontación con la absolutización tiránica del mundo concreto denunciada por Rosenzweig en la Introducción al tercer libro de La Estrella (EdR: pp. 319-353). Pues, en efecto, aquello que Rosenzweig reprocha a la tiranía no es otra cosa que, precisamente, su temporalización constitutivamente injusta, inoportuna (unrecht). ${ }^{18}$ El tirano no toma en serio el tiempo de los otros - esto es, el tiempo de Dios, del mundo y de los otros hombres-y, de este modo, es decir, a través de esta totalización o absolutización de su propio tiempo, traiciona el carácter relacional o diacrónico propio del tiempo que, a diferencia de aquél en el que acaecen sucesos, acaece por sí mismo (NP, 58). De lo que por consiguiente se trata, tanto en La Estrella como en el programa formativo rosenzweiguiano, es de una resistencia contra la tiranía, contra toda política, asimilacionista o sionista en el caso del judaísmo, que se conciba a sí misma como desprovista de toda limitación. Se trata, en consecuencia, de una des-historización del mundo y, en especial, del mundo judío: la disimilación, en defintiva, del mundo judío, reclamada por Rosenzweig en La Estrella y llevada a la práctica a través del Centro Libre de Estudios Judíos.

18 Me he ocupado con más detalle de esta cuestión en "La concepción mesiánica del tiempo histórico en La Estrella de la Redención y su alcance jurídico-politico" (2015b). 


\section{REFERENCIAS BIBLIOGRÁFICAS:}

Avineri, Schlomo. 1988. "Rosenzweig's Hegel Interpretation: Its Relationship to the Development of His Jewish Reawakening”. En Der Philosoph Franz Rosenzweig (1886-1929): Internationaler Kongress-Kassel 1986, II. Freiburg-Münche: Karl Alber, pp. 831-838.

Bensussan, Gérard. 2003. "Le Freies Jüdisches Lehrhaus de Francfort". En Confluences. Politique, histoire, judaïsme. Paris: Vrin, pp. 17-30.

Buber, Martin. 1916a. "Begriffe undWirklichkeit. Brief an Herrn Geh. Regierungsrat Prof. Dr. Hermann Cohen”, en Der Jude, 5, 1916, pp. 281-289

Buber, Martin. 1916b. "Zion, der Staat und die Menschheit. Bemerkungen zu Hermann Cohens Antwort”, en Der Jude, 7, 1916, pp. 425-433.

CASPER, Bernhard. 1985 "Zeit und Heil. Überlegungen zu Martin Heidegger und einigen gegenwärtigen jüdischen Denkern”. En Ebraismo Ellenismo Christianismo II. Padova: Cedam, pp. 173-195.

CASPER, Bernhard. 1996. "Ereignis (acaecimiento) en la concepción de Franz Rosenzweig y en el pensamiento de Martin Heidegger”. Trad. de Garrido Maturano, Ángel. En Escritos de Filosofía, 29-30, pp. 3-20.

CASPER, Bernhard. 2005. "Zeit und messianische Zeit. Zu einem Grundphänomen des religiösen Geschehens”. En Scientia et Religio. Religionsphilosophische Orientierungen. Dresden: Thelem, pp. 97-110.

CASPER, Bernhard. 2006. "Der Andere, der Dritte und die Bürgschaft für die Gerechtigkeit”. En Archivio di Filosofia LXXIV, 1-3, pp. 185-194.

Cohen, Hermann. 1924 [1880]. "Ein Bekenntnis in der Judenfrage". En Jüdische Schriften, II. Berlin: C. A. Schwetschke und Sohn, pp. 73-94.

Cohen, Hermann. 1924b. "Zur Begründung einer Akademie für die Wissenschaft des Judentums”. En Jüdische Schriften, II. Berlin: C. A. Schwetschke und Sohn, pp. 210-217.

COHEN, Hermann. 2010 [1916]. "Religión y sionismo. Unas palabras a mis correligionarios de religión judía. Respuesta a la carta abierta del Doctor Martin Buber dirigida a Hermann Cohen”. Trad. de Burello, Marcelo. En Mesianismo y razón. Escritos judios. Buenos Aires: Lilmod, pp. 261-279.

Derrida, Jacques, 2004. Acabados seguido de Kant, el judío, el alemán. Trad. de Peñalver, Patricio. Madrid: Trotta.

Glatzer, Nahum Norbert, 1961 [1953]. Franz Rosenzweig: His Life and Thought. New York: Schocken Books.

Gordon, Peter Eli, 2003. Rosenzweig and Heidegger. Between Judaism and German Philosophy. Berkeley-Los Angeles: University of California Press. 
KoHr, Jorg, 2008. “Gott selbst muß das letzte Wort sprechen...”. Religion und Politik im Denken Franz Rosenzweigs. Freiburg i. Br. - München: Karl Alber Verlag.

Löwith, Karl, 2006. "Martin Heidegger y Franz Rosenzweig. Un agregado a El ser y el tiempo (1942/1943)". En Heidegger, pensador de un tiempo indigente. Sobre la posición de la filosofia en el siglo XX. Trad. de R. Setton. Buenos Aires: FCE, pp. 91-126.

Meinecke, Friedrich. 1908. Weltbürgertum und Nationalstaat. Studien zur Genesis des deutschen Nationalstaates. Oldenbourg: München-Berlin.

Meinecke, Friedrich. 1982 [1936]. El historicismo y su génesis. Trad. de Mingarro y San Martín, José. México D. F.: Fondo de Cultura Económica.

Meinecke, Friedrich. 1983 [1924]. La idea de la razón de Estado en la Edad Moderna. Trad. de F. González Vicen. Madrid: Centro de Estudios Constitucionales.

Mendes-Flôhr, Paul, 1988. "Franz Rosenzweig and the Crisis of Historicism". En Id. (ed.), The Philosophy of Franz Rosenzweig. Hannover: University Press of New England, pp. 138-161.

Myers, David N. 2003. Resisting History: Historicism and his Discontents in German-Jewish Thought. Princeton: Princeton University Press-Woodstock.

Mosès, Stephane. 1987. "Hegel beim Wort genommen. Geschichtskritik bei Franz Rosenzweig”. En Zeitgewinn. Messianisches Denken nach Franz Rosenzweig. Frankfurt am Main: Knecht, pp. 67-89.

Mosès, Stephane.1988. "Politik und Religion. Zur Aktualität Franz Rosenzweigs". En Der Philosoph Franz Rosenzweig (1886-1929): Internationaler Kongre”sKassel 1986, II. Freiburg-München: Karl Alber, pp. 855-875.

Mosès, Stephane. 2003 [1982]. Système et révélation: la philosophie de Franz Rosenzweig. París: Bayard.

Navarrete Alonso, Roberto. 2015. "Franz Rosenzweig y la crisis del historicismo alemán”. En Pensamiento. Revista de investigación e información filosófica, LXXI, 265, pp 117-135.

Navarrete Alonso, Roberto. 2015b. "La concepción mesiánica del tiempo histórico en La Estrella de la Redención y su alcance jurídico político”. En: Actas del I Congreso Internacional de la Red Española de Filosofía. Valencia: Servicio de Publicaciones de la Universidad de Valencia (en prensa).

Navarrete Alonso, Roberto, y Lanceros Méndez, Patxi, 2015. "De Hegel a la Estrella: ahora, todavía, siempre”. En Rosenzweig, Franz: Escritos sobre la guerra. Trad. de Roberto Navarrete. Salamanca: Sígueme, pp. 203-225.

Pollock, Benjamin. 2014. Franz Rosenzweig's Conversions.World Denial andWorld Redemption: Indiana University Press.

Rosenzweig, Franz. 1979. Der Mensch und sein Werk. Gesammelte Schriften (I): Briefe und Tagebücher 1 (1900-1918) [GS I, 1]. Haag: Martinus Nijhoff. 
Rosenzweig, Franz. 1979. Der Mensch und sein Werk. Gesammelte Schriften (I): Briefe und Tagebucher 2 (1918-1929) [GS I, 2]. Haag: Martinus Nijhoff.

Rosenzweig, Franz. 1984. Der Mensch und sein Werk. Gesammelte Schriften (III): Zweistromland. Kleinere Schriften zu Glauben und Denken [GS III]. Haag: Martinus Nijhoff.

Rosenzweig, Franz. "El nuevo pensamiento. Observaciones adicionales a "La estrella de la redención” (1925)”[NP].Trad. de Isidro Reguera. En El nuevo pensamiento. Madrid: Visor, pp. 43-80.

Rosenzweig, Franz. 1997. La Estrella de la Redención [EdR]. Trad. de Miguel GarcíaBaró. Salamanca: Sígueme.

Rosenzweig, Franz. 1998. "Introducción a los escritos judíos de Hermann Cohen". Trad. de Miguel García-Baró. En Beltrán, M. - Mardones, J. M. - Mate, M. R. (eds.), Judaísmo y límites de la Modernidad. Barcelona: Riopiedras, pp. 13-64.

Rosenzweig, Franz. 2007. "Ya es hora. Ideas sobre el problema de la actual formación judía”. Trad. de Burello, Marcelo G. En Lo humano, lo divino y lo mundano. Escritos. Buenos Aires: Lilmod, pp. 29-53.

Rosenzweig, Franz. 2014. El país de los dos ríos. El judaísmo más allá del tiempo y la historia.Trad. de Ortega Rodríguez, Iván. Madrid: Encuentro.

Rosenzweig, Franz. 2015. Escritos sobre la guerra. Trad. de Roberto Navarrete. Salamanca: Sígueme.

Spinoza, Baruc, 1976. Tratado teológico. Trad. de Reus y Bahamonde, Emilio. Salamanca: Sígueme.

Strauss, Leo, 2008. Gesammelte Schriften I. Die Religionskritik Spinozas und zugehörige Schriften. Stuttgart-Weimar: J. B. Metzler.

Strauss, Leo, 2008b. Gesammelte Schriften III. Hobbes' politischeWissenschaft und zugehörige Schriften - Briefe. Stuttgart-Weimar: J.B. Metzler. 